\title{
Clinical and Histological Profile of Leprosy Patients at Rural Based Tertiary Care Centre in Post Elimination Era
}

\author{
Tanupriya Bindal ${ }^{1}$, Ivreet Kaur Kalra ${ }^{1}$, Monika Garg ${ }^{1 *}$, Aneet Mahindra ${ }^{2}$ and Rattan Nangia ${ }^{1}$ \\ ${ }^{1}$ Department of Pathology, MMIMSR, Mullana, Ambala, Haryana, India \\ ${ }^{2}$ Department of Dermatology, MMIMSR, Mullana, Ambala, Haryana, India
}

\begin{abstract}
Background: Despite India having achieved the national leprosy elimination goal of prevalence rate less than one case per 10000, the disease is still prevalent. Its diverse presentation depending on immune status of host warrants a clinico-histological correlation for diagnosis and start of proper therapy.
\end{abstract}

Aim: The present study was done with the aim to describe the spectrum of clinical and histological profile of leprosy patients especially in doubtful and difficult cases especially where the clinical diagnosis is not sufficient and, then, to correlate clinical and histological profile.

Methods: This study is a hospital based prospective study conducted on sixty newly diagnosed cases of leprosy. Skin biopsy was taken in each case and processed routinely. All the cases were stained with hematoxylin and eosin and modified Ziehl-Neelsen stain. Ridley-Jopling classification was used for diagnosis and typing of cases.

Results: In the present study consisting of 60 newly diagnosed leprosy patients, majority of the cases i.e. 18 (30\%) were in age group of 21-30 years with male: female ratio of 1.6:1. The most common type of skin lesion was plaque (50\%), followed by hypo-pigmented macule (33.3\%). The clinico-pathological concordance was maximum in Tuberculoid (TT) (100\%) followed by Lepromatous (LL) (80\%), Borderline lepromatous (BL) (72.7\%), Borderline tuberculoid (BT) (50\%) and Mid-borderline (BB) $(33.3 \%)$.

Conclusion: The overall clinicopathological concordance in present study is good (66.7\%). Thus, the correlation of clinical and histological features along with bacillary index is far more useful for accurate typing and therapy in leprosy patients.

\section{Keywords: Bacillus; Biopsy; Granulomatous Disease; Leprosy; Mycobacterium Leprae; Skin.}

\section{Introduction}

Leprosy is a chronic granulomatous disease caused by Mycobacterium leprae, affecting primarily the cooler parts of the body: skin, upper respiratory tract, anterior segment of the eye, superficial portions of peripheral nerves and testes. Leprosy has varied spectrum of clinico-pathological manifestations, depending upon the immunity status of the host. ${ }^{[1-3]}$

Leprosy is still endemic in South East Asia. The prevalence of leprosy globally in the first quarter of 2014 was $0.32 / 10,000$ population. ${ }^{[4-6]}$ Among new cases being detected, about $9 \%$ were children indicating continued transmission of disease. In India, the prevalence rate was detected to be $0.68 / 10,000$ population. ${ }^{[7]}$

Diagnosis of leprosy on clinical grounds is based on number and type of lesions along with the presence of nerve thickening. Leprosy is difficult to diagnose because of its varied clinical profile especially in early and borderline cases whereas, histology has well defined parameters. Thus, the histopathological examination with modified Ziehl-Neelsen (ZN) stain is considered as gold standard for confirmation of diagnosis and typing of the disease. Further, it also indicates the response of disease to the treatment. ${ }^{[8-10]}$ Due to variations in the clinical and histopathological spectrum of leprosy, the present study was planned in a rural tertiary care centre with the aim to describe the spectrum of clinical and histological profile of leprosy especially in doubtful and difficult cases where clinical diagnosis alone is not sufficient. Further, to assess the concordance between clinical and histological profile of leprosy cases.

\section{Materials and Methods}

The present prospective study was conducted on new cases of leprosy in a rural medical college in Haryana, in the Department of Pathology in association with Department of Dermatology over a period of 2 years ( $\left(1^{\text {st }}\right.$ June 2014 to $30^{\text {th }}$ May 2016). After obtaining the consent from the patient and ethical clearance from Institute Ethical Committee, detailed clinical data followed by examination was done by the dermatologist. Ridley and Jopling classification was used by the dermatologist to diagnose leprosy cases clinically. Skin biopsy was performed in all the cases of suspected leprosy. 
Inclusion criteria: The newly diagnosed cases of leprosy were considered for the study.

Exclusion criteria: Patients under treatment with anti-leprosy drugs were excluded.

The skin biopsies were fixed in $10 \%$ buffered formalin. After that the specimens were routinely processed, 3-5 microns thick paraffin sections were cut on a rotary microtome, dewaxed and stained with Hematoxylin and Eosin (H\&E) and Modified ZN stain. A detailed histopathological examination of H\&E stained slides was done by two pathologists independently without knowing the clinical diagnosis. The histological parameters like epithelioid cells, foam cells, granuloma, lymphoid cells, epidermotropism, grenz zone and nerve involvement were noted. Modified $\mathrm{ZN}$ stained slides were evaluated for detection of Lepra bacilli and bacteriological index was calculated. The histopathological features were recorded along with the results of the Modified ZN stain for diagnosis of the spectrum of Hansen's disease according to Ridley and Jopling classification. ${ }^{[9,10]}$ The clinical and histological diagnosis were correlated and compared with other previous studies in literature.

\section{Results}

Seventy skin biopsies were analyzed in present study, which were clinically suspected to be leprosy; ten cases were excluded. Among these ten cases, five cases had inadequate biopsy and Lepra bacilli were negative (sampling error). Three cases revealed mild chronic inflammation and negative for Lepra stain. Two cases were diagnosed as dermatitis and were negative for Lepra bacilli. Sixty cases of leprosy were considered for the analysis. The maximum incidence was seen in the age group of 21-30 years i.e. 18 cases $(30 \%)$ with male to female ratio 1.6. The lowest incidence was in $<20$ years age group i.e. 2 cases (3.3\%).Maximum number of patients in the present study were male i.e. 37 (61.7\%) followed by 23 females (38.3\%). The most common type of skin lesion was plaques in 30 patients $(50 \%)$. However, the hypopigmented macules were noted in 20 cases $(33.3 \%)$. The loss of sensation was observed in 55 patients $(91.6 \%)$. The common site of involvement was trunk in 20 patients (33.3) followed by forearms in 18 patients $(30 \%)$. The numbers of lesions were less than 5 in number in 23 patients $(38.3 \%)$ and more than 5 in 37 patients $(61.7 \%)$. Unilateral distribution of skin lesion was seen in 44 patients $(73.3 \%)$ whereas bilateral skin involvement was seen in 16 patients $(26.6 \%)$. The peripheral nerve enlargement (mainly ulnar nerve and lateral popliteal nerve) were seen in 23 cases (38.3\%).

Majority of the cases among those clinically diagnosed belonged to Borderline Tuberculoid (BT-36.7\%) followed by Erythema Nodosum Leprosum (ENL-20\%), Borderline
Lepromatous (BL-18.7\%), Type 1 reaction (10\%), Lepromatous Leprosy (LL-8.3\%), Mid-Borderline (BB-5\%) and Tuberculoid leprosy (TT-1.7\%) in the present study of 60 new cases of leprosy categorized in accordance with Ridley and Jopling classification.

The maximum number of cases were confirmed histopathologically as BL (21.7\%), when skin biopsy revealed the presence of foamy macrophages along with lymphoid cell and centered around adnexal structures (Figure 1A and 1B). Lepra bacilli were positive in $84.6 \%$ cases with bacillary index of $1+$ to $4+$.

The diagnosis of BT was made in $(20 \%)$ cases when the granulomas were composed of epithelioid cells admixed with lymphocytes and granulomas were less compact and modified ZN stain did not reveal any Lepra bacilli (Figure $2 \mathrm{~A}$ and $2 \mathrm{~B}$ ).

In 10 cases $(18.3 \%)$ the diagnosis of lepromatous leprosy was made when there were aggregates of foam cells along the adnexal structures. The grenz zone was present in the all cases. Modified ZN stain was positive in 10 out of 11 cases $(90.9 \%)$ with bacillary index ranging from $4+$ to $6+$ ( Figure 3).

The diagnosis of TT spectrum was given in three cases (5\%) when compact epithelioid cell granulomas were seen with cuff of lymphoid cells and giant cell involving nerve bundles and eroding epidermis (Figure 4). No Lepra bacilli were seen in these cases.

The diagnosis of BB was given in single case where the granulomas had sheets of epithelioid cells with lesser number of lymphocytes. Modified $\mathrm{ZN}$ was negative in such case.

The diagnosis of type 1 Lepra reaction was given in 10 cases which were characterized by presence of edema in the granulomas and epidermotropism. In 5 cases of upgrading reaction presence of giant cell along with intra dermal and intra granuloma edema was noted. Out of 5 Lepra bacilli positive cases of Type 1 reaction, 4 showed BI of $2+$ and 1 case showed BI of $1+$.

In 10 cases diagnosis of erythema nodosum leprosum was given where histology revealed dermal edema, neutrophilic infiltration and vasculitis on the background of macrophage granuloma. Amongst the ENL cases, 4 cases showed BI of 3+, 2 showed BI of $2+$ and 1 case each showed BI of $1+$ and $4+$.

In present study, the histological diagnosis was further correlated with clinical diagnosis (Table 1). The clinicopathological correlation was highest in TT (100\%) followed by Type 1 reaction and ENL (83.3\% each), LL (80\%), BL (72.7\%) BT (50\%) and BB (33.3\%). 
least stable because of changing immune status of the host. As a result, a variety of clinical lesions of different morphology may be found in Mid-borderline patient. Thus, this is important to correlate the histological findings with the skin lesions subjected to the biopsy. ${ }^{[18,20]}$

Table 1: Correlation of Clinical and Histopathological Diagnosis.

\begin{tabular}{|c|c|c|c|c|c|c|c|c|c|}
\hline \multirow[b]{2}{*}{ Clinical Diagnosis } & \multirow{2}{*}{$\begin{array}{l}\text { No. of } \\
\text { Cases }\end{array}$} & \multicolumn{7}{|c|}{ Histopathological Diagnosis } & \multirow{2}{*}{$\begin{array}{c}\text { Percentage } \\
\text { of Parity } \\
(\%)\end{array}$} \\
\hline & & TT & BT & BB & $\mathrm{BL}$ & LL & $\begin{array}{c}\text { Type } 1 \\
\text { Reaction }\end{array}$ & ENL & \\
\hline TT & 1 & 1 & - & - & - & - & - & - & 100 \\
\hline BT & 22 & 2 & 11 & - & 3 & 2 & 4 & - & 50 \\
\hline $\mathrm{BB}$ & 3 & - & - & 1 & - & 2 & - & - & 33.3 \\
\hline $\mathrm{BL}$ & 11 & - & - & - & 8 & 2 & 1 & - & 72.7 \\
\hline LL & 5 & - & - & - & 1 & 4 & - & - & 80 \\
\hline Type 1 Reaction & 6 & - & 1 & - & - & - & 5 & - & 83.3 \\
\hline ENL & 12 & - & - & - & 1 & 1 & - & 10 & 83.3 \\
\hline Total & 60 & 3 & 12 & 1 & 13 & 11 & 10 & 10 & 66.7 \\
\hline
\end{tabular}

Table 2: Comparison of the overall clinico-pathological concordance among leprosy patients of the present study with other studies.

\begin{tabular}{|c|c|c|c|c|}
\hline Author & Place & Study year & No. of biopsies & Correlation $\%$ \\
\hline Ridley \& Jopling ${ }^{[8]}$ & England \& Malaysia & 1966 & 82 & 68.3 \\
\hline Verma et al[22] & Haryana & 1981 & 30 & 66.7 \\
\hline Jerath \& Desai ${ }^{[23]}$ & Punjab & 1982 & 130 & 68.5 \\
\hline Bhatia et al[18] & Uttar Pradesh & 1993 & 1351 & 69.0 \\
\hline Kar et al ${ }^{[24]}$ & Maharashtra & 1994 & 120 & 70.0 \\
\hline Kalla et al ${ }^{[19]}$ & Rajasthan & 2000 & 736 & 64.7 \\
\hline Moorthy et al[11] & Karnataka & 2001 & 372 & 62.6 \\
\hline Pandya \& Tailor ${ }^{[25]}$ & Gujarat & 2008 & 50 & 58.0 \\
\hline Mathur et al[12] & Nepal & 2011 & 156 & 73.7 \\
\hline Mehta et al[26] & Gujarat & 2012 & 100 & 70.0 \\
\hline Giridhar et a[ ${ }^{[13]}$ & Punjab & 2012 & 100 & 60.2 \\
\hline Kumar et al[ ${ }^{[15]}$ & Rajasthan & 2014 & 423 & 62.9 \\
\hline Present study & Haryana & 2016 & 60 & 66.7 \\
\hline
\end{tabular}




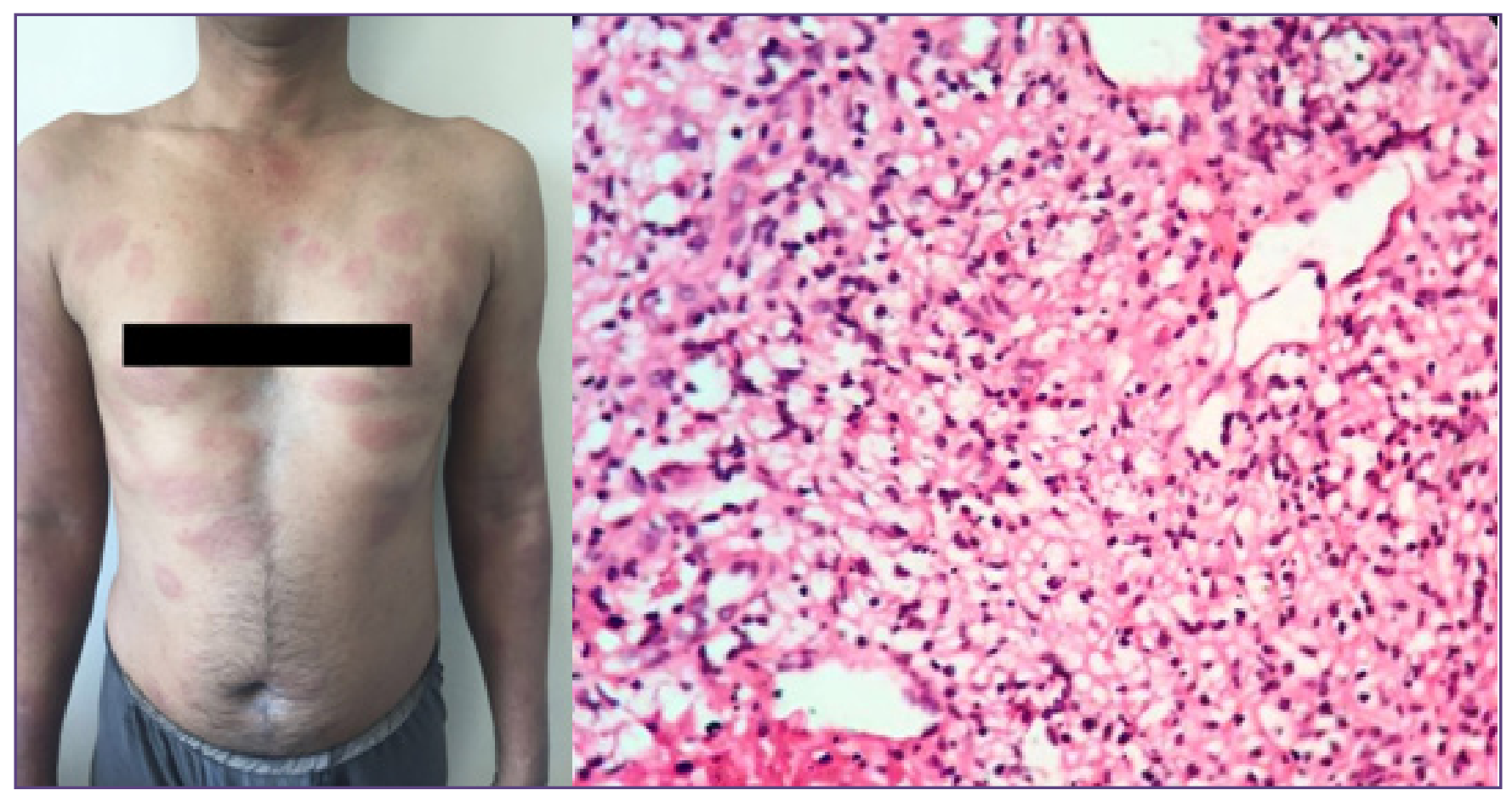

Fig. 1; (A) Case of borderline lepromatous leprosy, with multiple erythematous plaques on the trunk, which are symmetrical in distribution. (B) Photomicrograph of a borderline lepromatous leprosy (BL) revealing aggregates of foam cells along with lymphoid cells. (H\&E 400X).

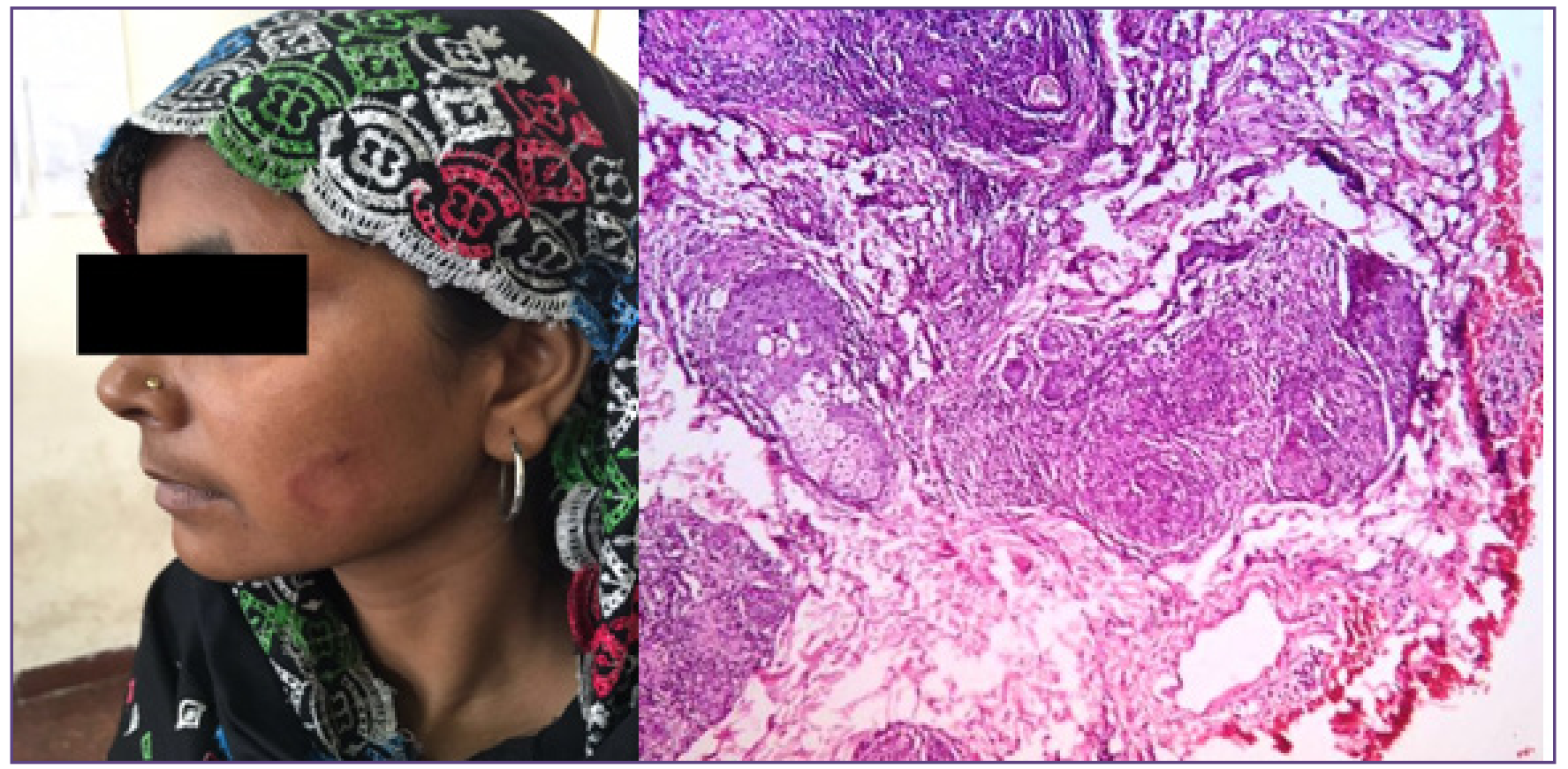

Fig. 2; (A) Case of borderline tuberculoid leprosy showing well to ill-defined plaque with erythematous borders present over left cheek. (B) Photomicrograph of borderline tuberculoid leprosy (BT) showing loose epithelioid cell granulomas with lymphoid cells around sweat glands. (H\&E 100X). 


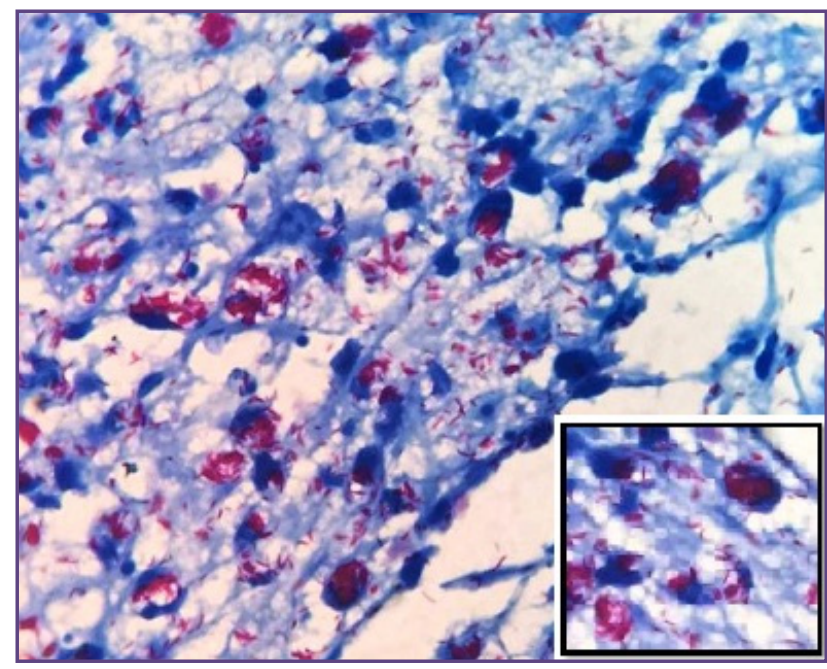

Fig. 3: Photomicrograph of modified Ziehl-Neelsen stain revealing globi of Lepra bacilli in lepromatous type of leprosy highlighted in inset. (Modified ZN 1000X).

In our study, the data was analyzed using Chi- Square test; $\mathrm{p}$ value comes out to be $<.001$ which is highly significant. On applying Kappa statistics, kappa value is 0.593 (which shows moderate strength of agreement). Strength of agreement was higher in TT, Type 1 reaction and ENL but was found lower in borderline group.

\section{Discussion}

Leprosy is considered a disease with different clinical manifestations depending on the cell mediated immune response of the host to the etiologic agent. Ridley and Jopling classification is well accepted in clinical practice and is based on immunological, bacteriologic and clinical parameters of leprosy. Histological classification of leprosy by Ridley and Jopling which divides leprosy into five groups gives a wellaccepted means of standardization between patients at widely distant centers. ${ }^{[8-10]}$ Thus, in the present study, we used Ridley and Jopling classification to categorize the cases clinically and histologically.

The present study consisted of 60 leprosy patients ranging from 18-75 years of age with male to female ratio of 1.6. Majority of the cases i.e. 18 (30\%) were in age group of 21-30 years and the least i.e. 2 cases (3.3\%) were below 20 years which is similar to the observations made in other studies. ${ }^{[1-15]}$ Due to long incubation period of leprosy and immunity pattern influenced by BCG (Bacillus Calmette Guérin) vaccination, the disease is rarely found among children.

In our study, among affected patients 37 were males $(61.7 \%)$ and 23 were females (38.3\%). Male preponderance

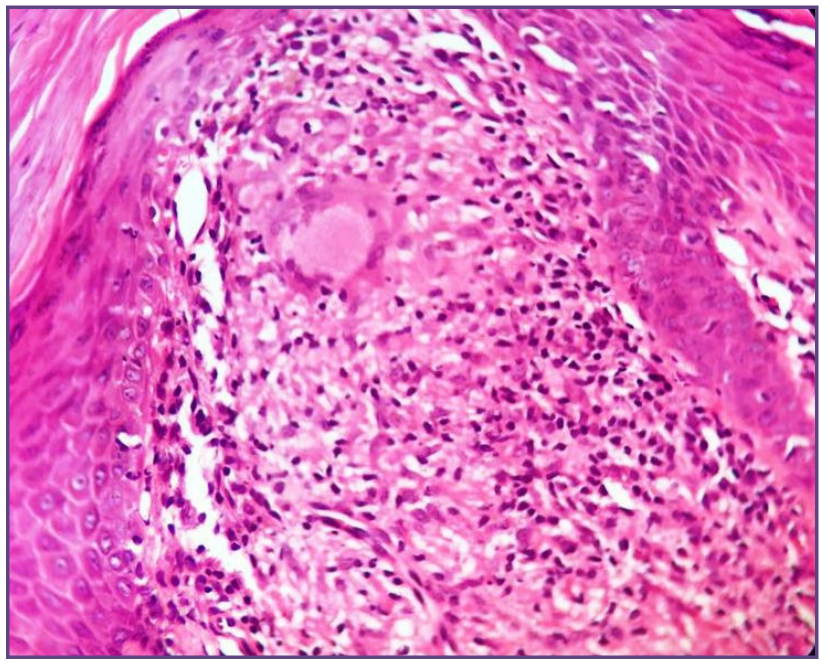

Fig. 4: Photomicrograph of skin biopsy of tuberculoid leprosy (TT) revealing epithelioid cell granulomas with lymphoid cells and giant cells eroding the overlying epidermis. (H\&E 400X).

was observed in many other studies. ${ }^{[1-15]}$ The dominance in males is because of the lifestyle; their vulnerability is because of greater mobility and increased opportunities for contact which is associated with greater risks of acquiring the infection. Social taboos and customs account for under detection of leprosy among females as lesser numbers report to the hospital for treatment. The disease is more common in females than males among all populations; this difference could be attributed to hiding of disease in females and gender difference in the immune status.

The most common clinical lesion present was plaque followed by hypopigmented macule which correlates well with clinical diagnosis of BT and study done by Bommakanti et al. ${ }^{[16]}$ The most common site for biopsy was trunk followed by forearm. Histological diagnosis was established in $92.3 \%$ cases in the present study by two pathologists, which is similar to other studies in literature. ${ }^{[17]}$ The overall clinicopathological correlation in our study was $66.7 \%$ i.e. there was complete agreement between clinical and histopathological diagnosis in 40 cases. Table 2 compares the clinicopathological concordance of present study with other studies in the literature.

Considering the data of present study maximum concordance (TT-100\%and LL-80\%) was observed in the polar group which is similar to other studies. ${ }^{[18,19]}$ This high rate of concordance can be attributed to stability of the lesion and well defined histological features. However, the least agreement of $33.3 \%$ was seen in cases of Midborderline leprosy. Mid-borderline type is considered the 
The difference in clinical and histological diagnosis is anticipated because the clinical categorization gives recognition only to the morphological appearance of skin lesions whereas histological categorization is more precise as its parameters are well-defined. The histological examination particularly is more significant in group of leprosy patients $(\mathrm{BT}+\mathrm{BB}+\mathrm{BL})$ where the immune status is continuously shifting. Here, the histological diagnosis gives better information about the subtype and any shift in the spectrum of the disease. Thus, it is important to study the skin biopsy from morphological lesion and serial biopsies from same or paired lesions to achieve better clinicopathological correlation. ${ }^{[18,20,21]}$

\section{Conclusion}

For definitive diagnosis of leprosy, there is need of histopathological diagnosis and demonstration of Lepra bacilli as clinical diagnosis offer difficulties particularly in early lesions. In the present study of 60 cases of leprosy, overall clinicopathological correlation is good (66.7\%). Thus, correlation of clinical and histological findings along with bacillary index is more helpful for exact categorization of disease than considering a single parameter which is necessary for deciding the type of therapy and knowing the response to the treatment in leprosy patients.

\section{References}

1. Bryceson A, Pfaltzgraff RE. Leprosy. 3rd ed. Edinburgh ; New York: Churchill Livingstone; 1990.

2. Woods GL, Myers WM. Mycobacterial Diseases. In: Anderson's Pathology. St. Louis: Mosby; 1996. page 84361.

3. Dharmendra, editor. Leprosy. 1st ed. Bombay: Kothari Medical Publishing House; 1978.

4. World Health Organisation. Global leprosy update, 2014: need for early case detection. Wkly Epidemiol Rec 2015;90(36):461-74.

5. Regional Office for South-East Asia. Global Leprosy Strategy 2016-2020. Accelerating towards a leprosy-free world. India: World Health Organization; 2016.

6. Expert Committee on Leprosy. Eighth report. Geneva: World Health Organization; 2012.

7. National Leprosy Eradication Programme - Progress Report for the year 2014-15. New Delhi: Central Leprosy Division, Directorate General of Health Services, Government of India; 2015.

8. Ridley DS, Jopling WH. Classification of leprosy according to immunity. A five-group system. Int J Lepr Other Mycobact Dis $1966 ; 34(3): 255-73$.
9. Lucas S. Bacterial Diseases. In: Lever's Histopathology of the Skin. Philadelphia: Lippincott Williams \& Wilkins; 2009. page 558-67.

10. Ridley DS. Histological classification and the immunological spectrum of leprosy. Bull World Health Organ 1974;51(5):451-65.

11. Moorthy BN, Kumar P, Chatura KR, Chandrasekhar HR, Basavaraja PK. Histopathological correlation of skin biopsies in leprosy. Indian J Dermatol Venereol Leprol 2001;67(6):299.

12. Mathur MC, Ghimire RBK, Shrestha P, Kedia SK. Clinicohistopathological Correlation in Leprosy. Kathmandu Univ Med J 2011;9(4):248-51.

13. Giridhar M, Arora G, Lajpal K, Chahal KS. Clinicohistopathological concordance in leprosy - a clinical, histopathological and bacteriological study of 100 cases. Indian J Lepr 2012;84(3):217-25.

14. Bijjaragi S, Kulkarni V, Suresh KK, Chatura KR, Kumar P. Correlation of clinical and histopathological classification of leprosy in post elimination era. Indian J Lepr 2012;84(4):271-5.

15. Kumar A, Negi SR, Vaishnav K. A study of Clinicohistopathological correlation of leprosy in a tertiary care hospital in western district of Rajasthan. J Res Med Dent Sci 2014;2(3):43.

16. Bommakanti J, Putta S, Gokhale S. Histopathological Relevance in Clinical Spectrum of Hansen's Disease. J Med Sci Clin Res 2016;4(12):14678-84.

17. Badhan R, Kundal RK, Raj RT, Bahl RK, Bal MS. A ClinicoPathological Correlation Study of Leprosy in a Tertiary Care Teaching Institute in Northwest Punjab, India. Am J Med Sci Med 2014;2(5):99-108.

18. Bhatia AS, Katoch K, Narayanan RB, Ramu G, Mukherjee A, Lavania RK. Clinical and histopathological correlation in the classification of leprosy. Int J Lepr Other Mycobact Dis 1993;61(3):433-8.

19. Kalla G, Salodkar A, Kachhawa D. Clinical and histopathological correlation in leprosy. Int J Lepr Other Mycobact Dis 2000;68(2):184-5.

20. Goyal S, Shah N, Shah FR, Shah NR, Shah CK, Shah JM. Clinicopathological Correlation with Histomorphological Spectrum and Bacillary Index of Skin Biopsy in Leprosy. Gujarat J Pathol Microbiol 2015;7:157.

21. Sandeep M, Murugesh S. A Study of Clinico-Pathological Concordance in Leprosy Patients in the Post-Elimination Era. Int J Sci Res 2016;5(2):1304-6.

22. Verma KC, Ganguli DD, Jain VK. Applicability of RidleyJopling scale in clinical practice. Lepr India 1981;53(4):55661.

23. Jerath VP, Desai SR. Diversities in clinical and histopathological classification of leprosy. Lepr India 1982;54(1):130-4. 
24. Kar PK, Arora PN, Ramasastry CV, Sayal SK, Dhaka RS. A clinico-pathological study of macular lesions in leprosy. Indian J Lepr 1994;66(4):435-42.
25. Pandya AN, Tailor HJ. Clinicohistopathological correlation of leprosy. Indian J Dermatol Venereol Leprol 2008;74(2):174.

26. Mehta B, Desai NJ, Khar S. Clinico-Pathological Corelation in Leprosy. Internet J Dermatol 2012;9(1):4.

*Corresponding author:

Dr Monika Garg, H.No.881, Sector 41-A, Chandigarh UT India

Phone: +919417378514

Email: monikakash7@yahoo.co.in

Financial or other Competing Interests: None. 